\title{
PEREIRA, A. B. “A Maior Zoeira” na escola: experiências juvenis na periferia de São Paulo. São Paulo: Editora Unifesp, 240p, 2016.
}

\section{Murilo Gelain Gonçalves ${ }^{1}$}

Conversas, gritos e risadas. É essa desordenada e incompreensível mistura de sons que anuncia a proximidade de uma escola. A incapacidade de se decifrar o que se ouve traz as primeiras questões: do que riem? Sobre o que conversam? Como contrapartida, a confusa sonoridade traz a primeira conclusão: a escola, por mais que tente se isolar do entorno, não consegue manter presos os sons produzidos ali dentro. Assim começa o livro "A Maior Zoeira" na escola: experiências juvenis na periferia de São Paulo, com a pesquisa de doutorado de Alexandre Barbosa Pereira, lançado em 2016 pela editora Unifesp.

Da mesma maneira que não consegue impedir que seus sons escapem ao mundo, o oposto também ocorre. O mundo lá de fora entra na escola. Ele entra pelos sons dos carros acelerando e das motos derrapando ou cortando giro nas ruas da quebrada (Pereira, 2010; 2016), entra pelos funks que tocam nos alto-falantes, também pelos corpos e nos bolsos e mochilas dos seus estudantes, e, por vezes, também entra pela farda da PM. Os altos muros, as grades, as câmeras de vigilância, os vigias, as dificuldades de entrar ou sair e demais elementos da sua arquitetura de controle e rotina disciplinar não impedem que o mundo entre na escola. O ambiente escolar, marcadamente metódico, formativo e controlador é contaminado por elementos alienígenas à essência da instituição. A malsucedida tentativa de se isolar do mundo lá fora não se reflete somente nos sons, mas em suas próprias dinâmicas internas. A instituição não consegue se manter totalmente dominante sobre o que acontece dentro dos seus limites. A invasão desses elementos estranhos provoca alterações no funcionamento do cotidiano escolar, e é isso que o autor buscou pesquisar. Ou, como ele mesmo disse, procurou observar "a apropriação da escola pelos jovens, o estabelecimento das redes de sociabilidade e a transformação da instituição de ensino a partir das práticas juvenis" (Pereira, 2016: 134).

\footnotetext{
${ }^{1}$ Universidade Federal do Rio Grande do Sul, Brasil
} 
Para isso, o autor se encaminhou a escolas públicas da periferia de São Paulo (Cidade Ademar, na Zona Sul e Brasilândia, na Zona Norte), além de ter utilizado também sua inserção como docente em uma escola particular na região centro-leste da cidade para a pesquisa de campo. Sabendo que, para compreender a escola, se faz necessário contextualizá-la, o pesquisador acompanhou os jovens em outros espaços, como lan houses, bares e festas de rua, transbordando a análise da pesquisa para além dos muros da escola a fim de compreender como os jovens experienciavam sua relação com o mundo que lhes era acessível, fosse presencial ou virtual, lançando mão de redes sociais virtuais também como fonte. A partir disso, as experiências escolares e juvenis logo demonstraram estarem intermediadas por outras experiências, principalmente a periférica, a lúdica e a tecnológica.

A conjunção do ensino público, que por si só já traz problemas estruturais por motivos de ordem política, e de outros fatores provenientes das idiossincráticas dinâmicas de periferia, resulta num conturbado cotidiano muito particular. Pereira traz relatos de professores da rede pública que expressam com exatidão suas angústias, dificuldades, irritações e decepções causados pela estressante vida docente que adoece, deprime e desestimula seus profissionais. O conflito está presente a todo momento, e muitas vezes, a entrada na sala de aula é entendida como numa arena onde o aluno não é visto somente como alguém a quem se ensina, mas um oponente com o qual se disputa atenção e a autoridade. O professor da rede pública, condenado à desvalorização salarial e a grandes jornadas de trabalho, se depara com o fato de que essa condição, em muitos momentos, é usada por seus próprios alunos como argumento para desqualificá-lo, desafiá-lo e destituílo de sua autoridade. Não são raras as piadas nesse sentido, onde o professor é rebaixado à uma condição de pobre coitado, de digno de pena e de infeliz por estar destinado a receber pouco e trabalhar demais. Essas lástimas aparecem em tom de deboche como antítese dos projetos de vida dos alunos, que têm em mente uma vida de riqueza, poder e prazer como objetivo, bastante influenciados pelo consumo de cultura de massas.

Esses momentos, percebidos como desrespeitosos pelos professores, expressam o que alguns docentes entendem como uma espécie de condição marginal propensa ao banditismo, à violência, à incapacidade de aprender e de mudar, e, em última instância, fadada ao fracasso profissional e social, que é naturalizada ao jovem de periferia. Essa percepção estigmatizada também se reforça com outras práticas juvenis, como os games 
que simulam ações criminosas e as músicas, que em muitos casos, proferem elogios a facções criminosas e narram delitos em tom de orgulho. Ou seja, ao fim, como consequência dos conflitos, muitos professores acabam confirmando certos preconceitos, seja de forma discreta, como em conversas entre seus pares na sala dos professores ou mais indiscretamente, em sala de aula com os alunos ouvindo.

Apesar de a relação conflituosa entre alunos e professor ser constante, o relacionamento entre professores e alunos não se resume a isso. Existem professores que buscam criar outros tipos de relações, pautadas em interações mais fraternas e pacíficas com os discentes. Tal estratégia, porém, não aparece como muito frutífera em alguns aspectos. Os relatos trazidos por Pereira concluem que aqueles professores que tentam ser amigos dos alunos, não obtêm sucesso em prosseguir com seus planejamentos de aula, sendo tão interrompidos e desafiados pelos alunos quanto os que adotam posturas mais conservadoras e distanciadas.

Essas relações, que muitas vezes tomam forma de disputas travadas com os professores e equipe escolar, se dão também entre os próprios alunos, porém, nesses casos (assim como quando se dirigem aos professores amigos), a interação não é necessariamente entendida como conflituosa. É nessas dinâmicas entre os alunos que está a principal contribuição e o núcleo de toda a reflexão da obra: a zoeira. Espécie nativa e contemporânea de relação jocosa tipicamente juvenil, a zoeira se apresenta como uma série de interações amistosas e lúdicas, porém ambivalentes, apresentando-se ora como simples brincadeiras, ora como algo mais agressivo, chegando até mesmo a se provocar embates.

Deve-se pontuar que a zoeira é uma forma entre outras tantas interações lúdicas presentes no cotidiano das relações dos alunos. De jogos de dominó a campeonatos de futebol, esse tipo de interação é de grande importância, servindo como momentos em que os laços afetivos são aprofundados em instantes prazerosos aos participantes e que tornam a maçante e tediosa rotina escolar mais suportável. É nesses momentos de intensificação das afinidades que os limites da intimidade são testados através de piadas e brincadeiras, ou seja, com um caráter de gozação. Como atesta Pereira quando conta que, a partir da sua participação de dinâmicas lúdicas, passou a ser alvo mais frequente de brincadeiras e então pôde visualizar melhor como opera a zoeira. 
Ancorado em debates da sociologia e da antropologia, Pereira constata que interações semelhantes são registradas em outros trabalhos com adolescentes em escolas. O autor discute essas práticas de sociabilidade sob duas perspectivas, uma mais disruptiva e negativa, outra mais positiva e conjuntiva. Concluindo ao fim que tais interações não se adequavam totalmente a nenhuma dessas perspectivas, porém, ao mesmo tempo, poderiam apontar para ambas. A motivação da zoeira então não é necessariamente criar uma disjunção nem integrar, mas sim, como eles dizem, causar (Pereira, 2016: 164). Isto é, desestabilizar a regularidade do cotidiano escolar, provocar rupturas na normalidade.

As piadas e as brincadeiras em tom de gozação são as principais formas que a zoeira assume em sala de aula. Apontar características físicas de forma cômica, imitar personagens de programas de humor da TV, simular conversas ou reproduzir sons de animais no celular, as formas de se zoar para causar são várias. Ao causar, os jovens que protagonizavam as piadas disputando a atenção com o professor, a direcionam para si mesmos, e assim se tornam populares entre os colegas. Esses palhaços, como são chamados por McLaren (1991) e cujo termo é importado por Pereira, conseguem converter esse seu prestígio em capital político, elegendo-se muitas vezes como representantes de turma. Há um ponto sobre as piadas que merece destaque que é a sua potencial caricaturização, o seu foco em transformar características físicas e corporeidades em um elemento jocoso. Nisso residem algumas questões. A ambiguidade que está colocada nesses casos. Os limites entre a uma brincadeira amigável e uma brincadeira agonística são muito tênues, tudo depende do contexto, da intensidade e de quem está envolvido (Pereira, 2016: 177). Outra questão que aparece nas zoeiras caricaturais é a reprodução de noções preconceituosas reproduzidas como simples piadas. A diversos momentos as piadas se baseiam em comentários homofóbicos, racistas, e elitistas quando características consideradas pelos jovens como negativas, inferiores ou indesejadas são evocadas em tom de humor.

A zoeira então, já que pode ser tanto uma gentileza quanto uma ofensa, carrega com si a indefinição do presente-veneno (Mauss, 2013). E, assim como toda relação de dádiva, exige uma contrapartida. Desse modo, a resposta de uma zoeira pode variar. 
Ou seja, em certos momentos a gozação poderia ser amistosa, feita apenas para romper o tédio e produzir risadas entre os amigos. Da mesma forma, a retribuição daquele que foi chacoteado também poderia ser amistosa, tendo em vista que se reconheceria que a intenção era apenas brincar. Em outros momentos, no entanto, a zoeira pode ter a intenção explícita de agredir quem quase sempre era considerado como rival. O que se procuraria nesses casos, era um desafio ao outro, que poderia responder - ou retribuir com outras gozações agressivas ou até com uma discussão, ou, em alguns casos mais extremos, com um confronto físico. (Pereira, 2016: 179)

Outro aspecto interessante da zoeira observada pelo autor é a sua divisão de gênero. Apesar de ser predominantemente protagonizada por meninos, as meninas também faziam, em menor grau, parte dos momentos lúdicos. Além do que, as suas zoeiras eram menos agressivas. O que demonstra, com base em outras pesquisas, que a propensão dos meninos em estabelecerem relações lúdico-performáticas sob a forma de violências lúdicas (como tapas, socos, chutes ou lutinhas) está relacionada com a performação de modelos hegemônicos de gênero. Em outras palavras, as zoeiras cumprem também o papel de treinar os meninos para suas performances masculinas dentro dos padrões que são esperados deles. Disso também resultam também as brincadeiras homofóbicas como forma de afirmar a heterossexualidade. A pesquisa de Pereira conclui que, mesmo a zoeira sendo uma prática juvenil com potencial contra-hegemônico, elas carregavam também um potencial hegemônico, porque reproduzem certas noções opressivas e dinâmicas de dominação.

Creio ser de importância, além de apresentar a obra, mencionar como o conceito apresentado por Pereira pode ser adequado para pensar os fenômenos de sociabilidade juvenil em outros contextos além dos por ele observados. Por exemplo, um relato com o qual me deparei numa rede social há alguns dias. Uma estudante universitária publicou em seu mural o seguinte texto:

Na parada de ônibus, o diálogo entre quatro adolescentes de uns 13,14 anos:

- E aí meu, e as namoradas?

- O que tu quer saber das namoradas dele, meu, tá interessado?

- Não, eu não namoro preto

- Que preconceito é esse?

- Ele não namora preto, só namora branco.

- AAAAAEEEEEEAAAAA PUTÃO!!

E eu tô até agora pensando... (Retirado da internet) 
A conversa apresentada elucida com apuro do que se trata a obra de Pereira. É um exemplo claro de como a zoeira está presente nas relações dos jovens contemporâneos e como ela se manifesta entre os meninos evocando questões relativas à raça e sexualidade. Questiona-se a fidelidade e o pertencimento do outro ao grupo heterossexual a partir de uma pergunta banal (e as namoradas?), sugerindo-se um possível e implícito interesse homossexual. O questionamento, por sua vez, é respondido em tom de agressividade (provavelmente ainda dentro dos limites aceitáveis para a brincadeira), centrando a resposta numa negativa por critério de raça. Feito isso, um outro sujeito questiona o explícito teor preconceituoso na fala anterior, e é complementada por uma afirmativa da primeira zoeira, que confirmaria o interesse homossexual por brancos, já que somente os negros haviam sido mencionados pelo respondente na sua fala. A conversa toda gira em torno de provocações e testes em forma de piadas, e termina com uma comemoração geral que deve ter trazido risos ao grupo todo. Fora da zoeira, a descrição dessa conversa só poderia ser entendida como reprodução de preconceitos e deseducação, ou, como a autora da publicação comentou, expressão de "uma geração intoxicada de preconceitos". Já, com a categoria trazida pelo livro, pode-se compreender de outra forma o que se manifesta na experiência dos agentes envolvidos.

Um outro objeto que pode ser analisado a partir da categoria zoeira são os embates políticos efetuados no campo da internet, como, por exemplo, o fenômeno da utilização dos memes em discussões de caráter ideológico. É inegável que as práticas em campo virtual têm influenciado em algum grau a política na sua forma tradicional e institucional. Talvez, sob a luz da zoeira, possamos estar mais preparados para compreender a popularização de certas figuras políticas que fazem sucesso entre jovens e reproduzem também determinadas concepções hegemônicas de masculinidade, agressividade, heterossexualidade e dominação.

Enfim, múltiplas possibilidades aparecem como desdobramentos do uso desse conceito para o estudo de importantes fenômenos sociais contemporâneos relativos à juventude. A obra de Pereira, ao apoiar-se sobre diferentes campos do conhecimento e dissertar sobre muitos aspectos relacionados com as experiências juvenis e escolares, se mostra de grande valor para pesquisadores da antropologia, da sociologia e também para 
educadores, além de contribuir para debates relacionados à juventude, educação, consumo, tecnologia, gênero e violência.

\section{Referências}

MAUSS, Marcel. Ensaios de Sociologia. São Paulo: Perspectiva, 2003.

MCLAREN, Peter. Rituais na Escola: Em Direção a uma Economia Política dos Símbolos e Gestos na Educação. Petrópolis, Vozes, 1991.

PEREIRA, Alexandre Barbosa. "A Maior Zoeira” na escola: experiências juvenis na periferia de São Paulo. São Paulo: Editora Unifesp, 2016.

. As Marcas da Cidade: Dinâmicas da Pixação em São Paulo. Lua Nova, São Paulo, 79: 143-162, 2010.

Recebido em: 23/05/2017.

Aprovado em: 01/08/2017. 